\title{
Effect of Shock Wave in Treatment of Sciatic Neuralgia
}

\author{
Authors \\ H S Abd El-Salam ${ }^{1}$, W T Mansour ${ }^{2}$, G S El-Morsi ${ }^{3}$, HAA Shaker ${ }^{4}$ \\ ${ }^{1}$ Physiotherapist at National nutrition institute, Cairo, Egypt \\ ${ }^{2,4}$ Professor in the Department of Physical Therapy for Neuromuscular Disorders and its Surgery, Faculty of \\ Physical Therapy, Cairo University, Egypt \\ ${ }^{3}$ Consultant of orthopedic surgery at Ahmed Maher Hospital, Faculty of Medicine, Cairo University, Egypt
}

\section{Abstract}

Sciatica is a relatively common condition with a lifetime incidence varying from $13 \%$ to $40 \%$. The corresponding annual incidence of an episode of sciatica ranges from $1 \%$ to $5 \%$.

Objective: of this study was to to determine the effect of shock wave in treatment of sciatic neuralgia in Egypt Methods: Thirty male and female patients suffering from sciatic neuralgia were assigned randomly into two equal groups. Study group $(G A)(n=15)$ and control group $(G B)(n=15)$. The group $(A)$ received shock wave and therapeutic exercise, the patients in group (B) received therapeutic exercise only. Parameter of pain assessment through visual analogue scale and balance stability through biodex stability system were measured before and after four weeks of treatment for both groups.

Design: prospective Two groups pre-post design

Results: post treatment results showed there was significant decrease in pain and significant improve in balance overall stability index, medio /lateral stability and antro-post stability in the study group. There was no significant improvement in pain and stability index in the control group.

Conclusion: I t can be concluded that shock wave is effective as a method of treatment of sciatic neuralgia.

Keywords: Sciatic neuralgia, Pain, Balance, Shockwave.

\section{INTRODUCTION}

Sciatica is pain that radiates from the buttock downward along the course of the sciatic nerve but the term has been used indiscriminately for a variety of back and leg symptoms ${ }^{(1)}$.

Sciatic neuralgia is defined as pain in the distribution of the sciatic nerve due to pathology of the nerve itself'. Radicular pain is defined as 'pain perceived as arising in a limb or the trunk caused by ectopic activation of nociceptive afferent fibres in a spinal nerve or its roots or other neuropathic mechanisms'. According to these definitions, sciatic neuralgia is clearly a form of radicular pain, and is described as a disease of the peripheral nervous system ${ }^{(2)}$.

Extracorporeal shockwave therapy (ESWT) has shown effectiveness in many orthopedic disorders including soft tissue tendinopathy and non-union of long bone fractures ${ }^{(3,4)}$. Accordingly, shock waves are characterized by (A) high positive peak pressure $(\mathrm{P}+)$, sometimes more than 100 megapascals (MPa) but more often approximately 50 to $80 \mathrm{MPa}$,(B) fast initial rise in pressure (Tr) during a period of less than 10 nano second (ns), (C) low tensile amplitude ( $\mathrm{P}-$, up to $10 \mathrm{MPa})$, 
(D) short life cycle (I) of approximately 10micrsecond $(\mu \mathrm{s})$,(E) broad frequency spectrum, typically from $16 \mathrm{~Hz}$ to20 megahertz $(\mathrm{MHz})^{(5)}$ Shock waves have both a direct and indirect effect on treated tissues. The direct effect is the result of the energy of the shock wave being transferred to the targeted tissues. The indirect effect is the result of the production of cavitations bubbles in the treated tissue. Both the direct and indirect effects produce a biological response in the treated tissues (6).

\section{SUBJECTS AND METHODS}

Thirty patients (male and female) with sciatic neuralgia had been selected. They referred to physical therapy by Neurologist from outpatient clinic of faculty of physical therapy, Cairo University. These patients had been randomly (one by one for each group) divided into two equal groups.

Subjects included in the study their ages ranging from 30- 50 years. They were diagnosed as sciatic neuralgia based on careful clinical assessment and radiological investigations including X-ray and/ or magnetic resonance imaging (MRI).

The duration of illness ranged from one to six month. Straight leg raising test (Lasègue's test), (Fajersztajn's test), Bechterew test had been selected from the pain provocation tests \& were applied to all the patients on both sides. All patients were medically and psychologically stable.

Exclusion criteria were Perceptual, cognitive disorders, uncooperative patients, Patients with phobia from shock wave. Patients with any spinal causes of low back pain. Patients with fixed contractures in lower limbs.

\section{INSTRUMENTATION AND MATERIALS}

Biodex stability system (BSS) had been used for objective assessment of balance.

Visual analogue scale (VAS): had been used to measure the amount of pain that the patient feels ranges across a continuum line from none to an extreme pain.

Shock wave therapy had been used as a treatment instrument for the study group.
Therapeutic exercise had been done for both group, consist of strengthening and stretching exercise.

\section{STUDY PROTOCOL}

Group A (study group) treatment: Fifteen patients had received the shock wave and therapeutic exercise. For shock wave the patient lye in a prone lying position, Common ultrasound gel was used as a contact medium between the cylinder and the skin.2000 impulse, energy level 3-5 bar, were administered to the sciatic nerve distribution, two times per week for successive four weeks and therapeutic exercise two times per week for successive four weeks.

Group B (control group) treatment: Fifteen patients had received therapeutic exercise only three times per week for successive four weeks.

\section{ETHICAL CONSIDERATION}

All patients were informed of the purpose, tools, procedures, and duration of the study and signed a written consent

\section{STATISTICAL ANALYSIS}

Non parametric test and measures was used (Median and Inter quartile range IQR) and wilcoxcon measures inside the group and Mann whitteny test between groups .The six variables (stability index , Antro/ posterior stability index , Medio/ lateral stability index , standard deviation, Antro/ posterior standard deviation , Medio/lateral standard deviation) were compared between groups, The biodex results in between the study and control groups on affected side and non affected side, The visual analogue scale to compare between boths groups in pre and post treatment.

\section{Biodex Stability Results}

a) Comparison between study and control group (Affected side)

As presented in table (1) and illustrated in figure(1), Results revealed that there was no significant difference between both groups in pre treatment evaluation, in either affected or non 
affected side .In post treatment evaluation, there study group with $\mathrm{P}$ value $0.002 * *$. There was also significant difference in Antro-posterior stability index with $\mathrm{P}$ value $0.004^{* *}$.The medio- lateral was significant difference in stability index in the stability index of the study group had shown significant difference with $\mathrm{P}$ value $0.005^{* *}$.

Table (1) Comparison between study and control group (Affected side)

\begin{tabular}{|l|c|c|c|c|c|c|c|}
\hline \multirow{2}{*}{ Variable } & \multicolumn{2}{|c|}{ Control } & \multicolumn{2}{c|}{ Study } & \multirow{2}{*}{$\begin{array}{c}\text { P- } \\
\text { value }\end{array}$} & Indication \\
\cline { 2 - 8 } & Median & IQR & Median & IQR & & 0.339 & Not Sig. \\
\hline st_pr.aff & 3.60 & 1.70 & 3.70 & 2.20 & -0.957 & $0.002 * *$ & Sig. \\
\hline st_po.aff & 3.60 & 1.60 & 2.30 & 1.40 & -3.095 & 0.00 .17 & Not Sig. \\
\hline st_ap.pr-aff & 3.10 & 1.10 & 3.40 & 2.50 & -1.372 & 0.17 \\
\hline st_ap.po-aff & 3.10 & 0.70 & 2.10 & 0.90 & -2.874 & $0.004^{* *}$ & Sig. \\
\hline st_ml.pr-aff & 4.60 & 2.40 & 5.60 & 2.60 & -0.125 & 0.901 & Not Sig. \\
\hline st_ml.po-aff & 4.80 & 2.40 & 3.10 & 1.30 & -2.807 & $0.005^{* *}$ & Sig. \\
\hline sd_pr.aff & 1.50 & 0.60 & 1.50 & 0.30 & -0.063 & 0.95 & Not Sig. \\
\hline sd_po.aff & 1.60 & 0.60 & 0.60 & 0.40 & -3.761 & $0.001 * *$ & Sig. \\
\hline sd_ap.pr-aff & 2.30 & 0.90 & 1.90 & 1.60 & -0.817 & 0.414 & Not Sig. \\
\hline sd_ap.po-aff & 2.50 & 1.40 & 1.20 & 0.40 & -3.698 & $0.001 * *$ & Sig. \\
\hline sd_ml.pr-aff & 0.80 & 0.90 & 1.60 & 1.10 & -1.2 & 0.23 & Not Sig. \\
\hline sd_ml.po-aff & 0.90 & 1.10 & 0.60 & 0.40 & -2.272 & $0.023 *$ & Sig. \\
\hline
\end{tabular}

Figure (1) Comparison between study and control group (Affected side)

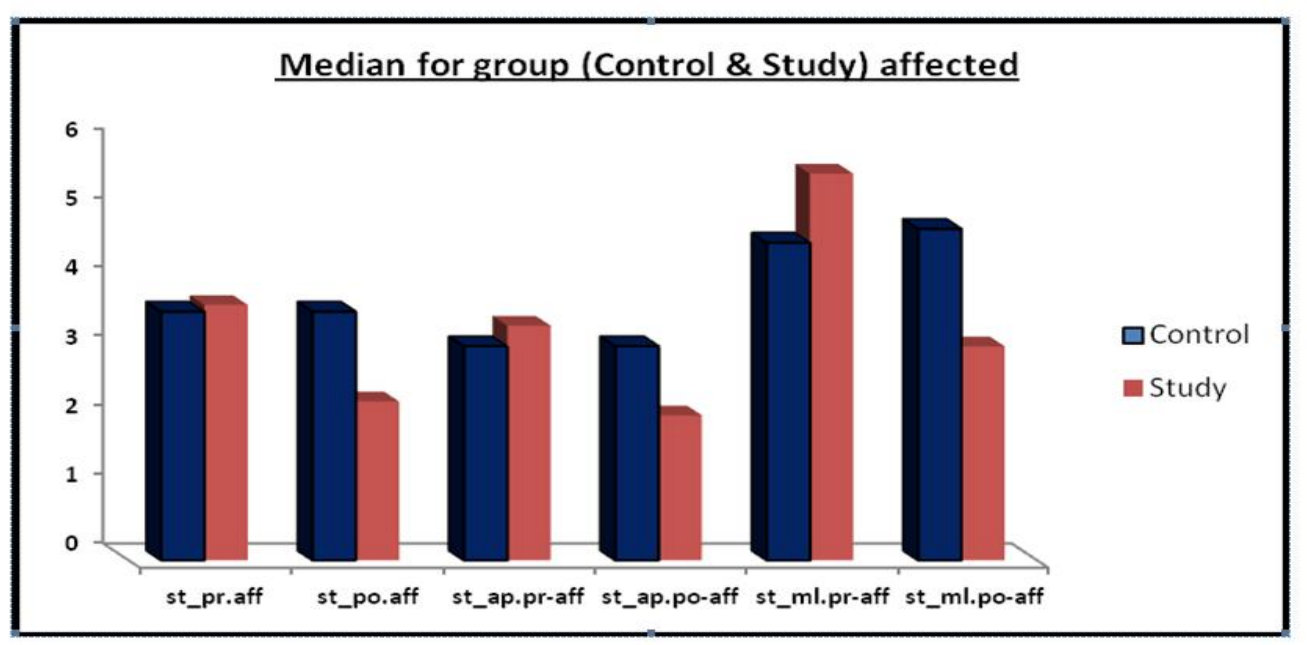

b) Comparison between study and control group (Non Affected Side)

As represented in table (2) and illustrated in figure

(2) there was no difference between both groups on pre assessment evaluation for non affected side, the both groups were homogenous. Post assessment there was significant difference in study group represented in over all stability index and medio lateral stability index, there was no increase in both groups in antro posterior stability index. 
Table (2) Test for the difference between group (study \& control) for non affected

\begin{tabular}{|c|c|c|c|c|c|c|c|}
\hline \multirow{2}{*}{ Variable } & \multicolumn{2}{|c|}{ Control } & \multicolumn{2}{|c|}{ Study } & \multirow{2}{*}{$\mathbf{Z}$} & \multirow{2}{*}{$\begin{array}{c}\text { P- } \\
\text { value }\end{array}$} & \multirow{2}{*}{ Indication } \\
\hline & Median & IQR & Median & IQR & & & \\
\hline st_pr.non-aff & 4.10 & 1.90 & 3.60 & 1.10 & -1.497 & 0.134 & Not Sig. \\
\hline st_po.non-aff & 3.90 & 1.60 & 3.70 & 1.20 & -2.02 & $0.043 *$ & Sig. \\
\hline st_ap.pr-non-aff & 1.70 & 2.40 & 2.90 & 1.60 & -0.252 & 0.801 & Not Sig. \\
\hline st_ap.po-non-aff & 1.80 & 2.60 & 2.00 & 0.50 & -0.187 & 0.851 & Not Sig. \\
\hline st_ml.pr-non-aff & 3.90 & 0.60 & 3.90 & 1.70 & -0.638 & 0.524 & Not Sig. \\
\hline st_ml.po-non-aff & 3.90 & 0.60 & 2.60 & 1.50 & -3.21 & $0.001 * *$ & Sig. \\
\hline sd_pr.non-aff & 0.70 & 0.20 & 0.70 & 0.40 & -0.958 & 0.338 & Not Sig. \\
\hline sd_po.non-aff & 0.60 & 0.30 & 0.40 & 0.30 & -1.486 & 0.137 & Not Sig. \\
\hline sd_ap.pr-non-aff & 1.20 & 0.40 & 1.20 & 1.40 & -0.627 & 0.531 & Not Sig. \\
\hline sd_ap.po-non-aff & 1.10 & 0.60 & 0.90 & 0.30 & -2.11 & $0.035^{*}$ & Sig. \\
\hline sd_ml.pr-non-aff & 0.90 & 0.70 & 0.70 & 0.60 & -1.693 & 0.091 & Not Sig. \\
\hline sd_ml.po-non-aff & 0.80 & 0.90 & 0.60 & 0.40 & -2.132 & $0.033 *$ & Sig. \\
\hline \multicolumn{5}{|c|}{ Significant Level $(\mathrm{P}<0.05)$} & \multicolumn{3}{|c|}{ Affected } \\
\hline \multirow{2}{*}{$\begin{array}{l}\text { Signifi } \\
\text { Medio/ }\end{array}$} & $\operatorname{vel}(\mathrm{P}<0$ & & \multicolumn{2}{|c|}{ St } & \multicolumn{3}{|c|}{ Stability Index } \\
\hline & & & \multicolumn{2}{|c|}{ SD } & \multicolumn{3}{|c|}{ Standard deviation } \\
\hline
\end{tabular}

Figure (2) Comparison between study and control group (Non Affected Side)

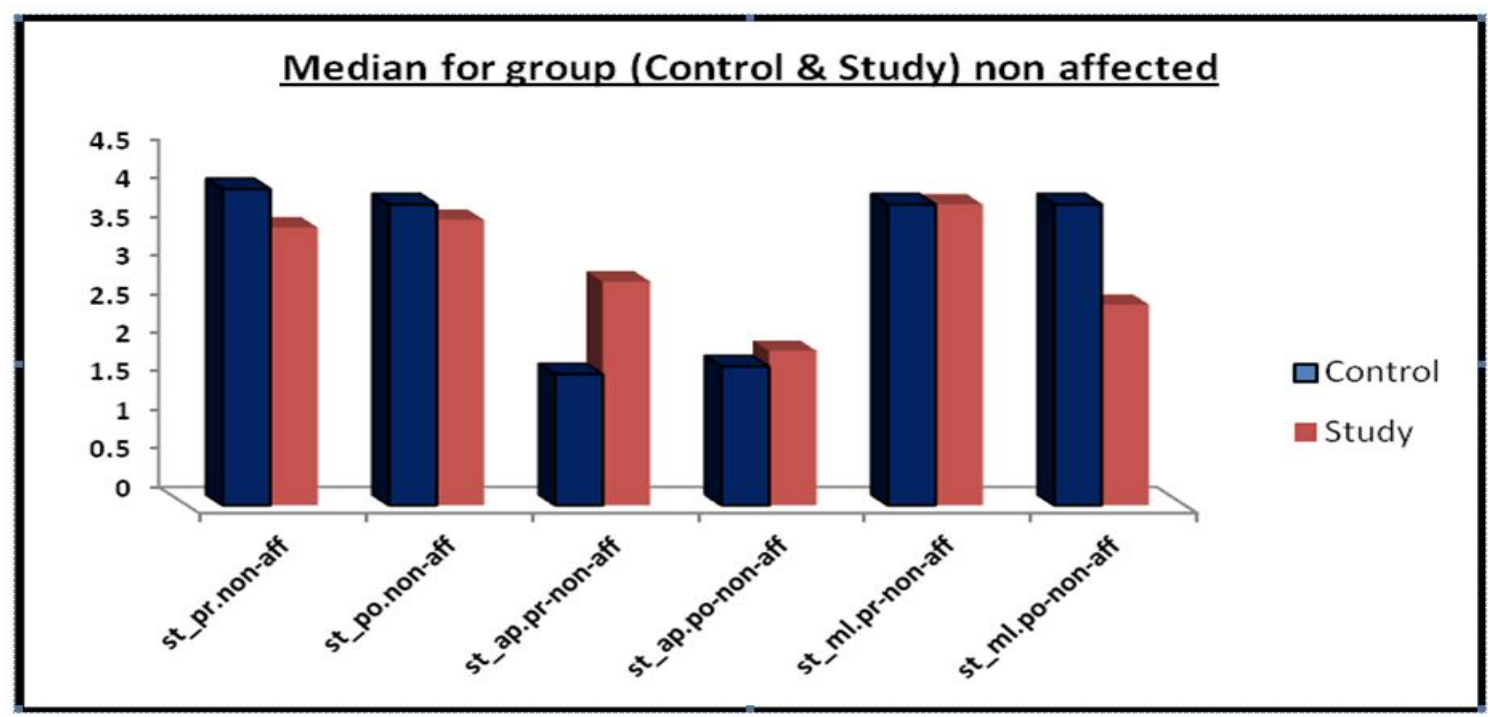

Visual analogue scale (VAS) results

As showed in table (3) and illustrated in figure (3) there was significant improvement in pain in the study group rather than control group.

Table (3) test for the difference between group (study \& control) for VAS

\begin{tabular}{|l|c|c|c|c|c|c|c|}
\hline \multirow{2}{*}{ Variable } & \multicolumn{2}{|c|}{ Control } & \multicolumn{2}{c|}{ Study } & \multirow{2}{*}{$\mathbf{Z}$} & \multirow{2}{*}{$\begin{array}{c}\text { P- } \\
\text { value }\end{array}$} & Indication \\
\cline { 2 - 5 } & Median & IQR & Median & IQR & & 0.43 & Not Sig. \\
\hline visua.pre & 8.00 & 1.00 & 8.00 & 2.00 & -0.79 & $0.001 * *$ & Sig. \\
\hline visua.post & 8.00 & 1.00 & 5.00 & 2.00 & -4.31 & 0.001 \\
\hline
\end{tabular}

** Significant Level $(\mathrm{P}<0.01)$ 
Figure (3) Comparison between study and control group

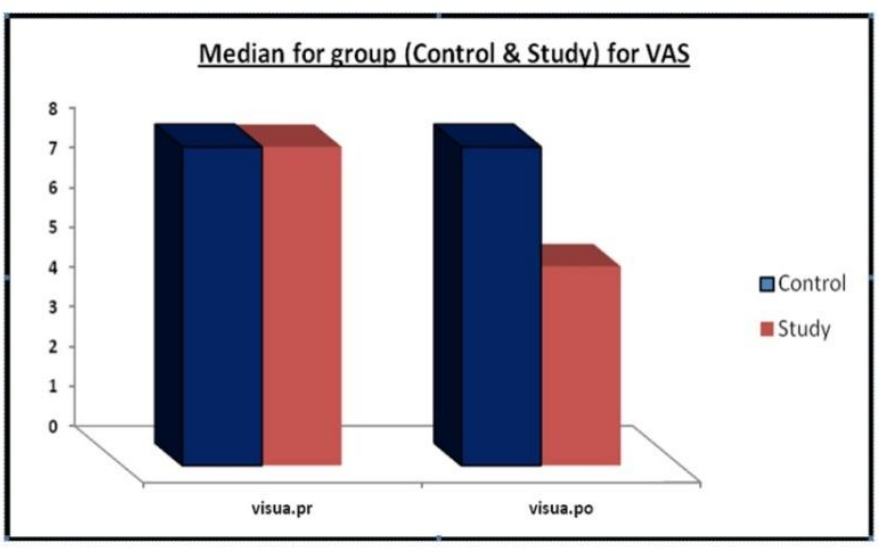

\section{DISCUSSION}

Sciatica affects many people. The most important symptoms are radiating leg pain and related disabilities. Patients are commonly treated in primary care but a small proportion is referred to secondary care and may eventually have surgery. Many synonyms for sciatica appear in the literature, such as lumbosacral radicular syndrome, ischias, nerve root pain, and nerve root entrapment (7)

In this study, there were no statistical significant differences between two groups in pre treatment evaluation; this indicates that the subjects in the two groups were homogenous. Comparing the pre-treatment and the post-treatment visual analogue scale result for study group; there was significant decrease in pain intensity in the study group with P Value $0.001^{*}$. This could be attributed to the effect of shockwave in pain reduction. This comes in close agreement with Schlaudraff KU et al, $2014{ }^{(8)}$ who studied the effectiveness of shock wave in patient with low back pain, the pain was reduced following shockwave after 8 sessions in the form of 2,000 shockwave impulses $(5 \mathrm{~Hz})$ at an energy flux density of $0.10 \mathrm{~mJ} / \mathrm{mm} 2$ were delivered using a 17-mm head.

The improvement of balance stability in study group rather than control group could be attributed to the effect of shock wave to improve the balance, this come in close agreement with Sangyong Lee et al., $2014{ }^{(9)}$ who studied the effects of extracorporeal shockwave therapy on patients with
Chronic Low Back Pain and their dynamic Balance Ability in which the patients divided into an extracorporeal shockwave therapy group (ESWTG: $\mathrm{n}=13$ ) and a conservative physical therapy group (CPTG, $n=15$ ). An exercise program that included Williams' exercises and McKenzie's exercises was performed by both groups. The program was implemented twice a week for six weeks. The visual analog scale (VAS) was used to measure the chronic low back pain of the patients. In the VAS comparison between the groups after the treatment, the ESWTG showed a significantly larger improvement in dynamic balance ability. The improvement in pain and function in study group rather than control group could be attributed to the effect of shock wave in decrease pain and inflammation and improve the function, this comes in close agreement with Chan Park et al.2015 ${ }^{(10)}$ who studied the effect of extracorporeal shockwave on frozen shoulder patients' pain and functions. Thirty frozen shoulder patients were divided into two groups: an extracorporeal shock wave therapy group of 15 patients and a conservative physical therapy group of 15 patients. The ESWT group, The patients received 1,000 shock waves at $2.5 \mathrm{~Hz}$, with the energy adjusted from $0.01-0.16 \mathrm{~mJ} / \mathrm{mm} 2$, depending on the degree to which the patients endured pain, two times per week for six weeks, In intra-group comparisons, the two groups showed significant decreases in terms of visual analog scales and patient-specific functional scales, although the extracorporeal shock wave therapy group showed significantly lower scores than the conservative physical therapy group. Extracorporeal shock wave therapy is considered an effective intervention for improving frozen shoulder patients' pain and functions.

The results of the present study were in consistent with Hammer DS et al., $2000^{(11)}$ who studied the effect of extra corporeal shockwave in patient with tennis elbow and painful heel. Both groups received 3000 shock waves of $0.12 \mathrm{~mJ} / \mathrm{mm} 2$ three times at weekly intervals. After a follow-up of 5 and 6 months respectively, pain measured on a visual analogue scale (VAS) decreased 
significantly in both groups. The success rate (excellent and good results) was $63 \%$ in tennis elbows and $70 \%$ in painful heels. ESWT seems to be a useful conservative alternative in the treatment of both conditions.

The results of the present study are in contradiction with the finding of Speed CA et al., $2002^{(12)}$. They studied the effect of extra corporeal shock wave therapy (ESWT) for patients with lateral epicondylitis. Adults with lateral epicondylitis were randomised to receive either active treatment (1500 pulses ESWT at $0.12 \mathrm{~mJ} / \mathrm{mm} 2$ ) or sham therapy, monthly for three months. All were assessed before each treatment and one month after completion of therapy. Outcome measures consisted of visual analogue scores for pain in the day and at night. Seventy-five subjects participated and there were no significant differences between the two groups at baseline. Both groups showed significant improvements from two months. No significant difference existed between the groups with respect to the degrees of change in pain scores over the study period. At three months, 50\% improvement from baseline was noted in $35 \%$ of the ESWT group and $34 \%$ of the sham group with respect to pain. It seems that the number of sessions was not enough to produce effect as the patients had received on session per month for three months so the total number of sessions was not enough to produce effect and the gap between sessions was too large (one month) which can affect on the result.

The result of statistical analysis of the current study showed that the shock wave had significant effect on sciatic neuralgia rather than therapeutic exercise, as there was a significant improvement of the affected side in single leg stance study group presenting in the overall stability and mediolateral stability and antro-post stability.

The present findings, shock wave had significant effect in improvement in overall stability index, Medio-lateral stability index and Antro -post stability in patient with sciatic neuralgia and pain reduction.

\section{ACHNOWLEGEMENT}

This study was completed with the collaborative and team work of my department of neuromuscular disorders and Its surgery, special thanks to Dr. Hussien Ahmed shaker for his constant motivation and advice.

\section{CONCLUSION}

Based on the results and finding of this study, it is possible to conclude that: The extra corporeal shock wave therapy is an effective method to decrease pain and inflammation and improve the balance in patients with sciatic neuralgia and beneficial method in treating sciatic neuralgia more than therapeutic exercise alone.

\section{REFERENCES}

1. Frymoyer JW,Back pain and sciatica .J. NEJ,318:291-300,1988.

2. Miranda H, Viikari-Juntera E, Martikainen $\mathrm{R}$, Takala E, Riihimaki H, Individual factors, occupational loading, and physical exercise as predictors of sciatic pain.J. Spine, there.9: 27-1102,2002.

3. Wang CJ. An overview of shock wave therapy in musculoskeletal disorders, j. Chang Gung Med.ther.26:220-232, 2003.

4. Wang CJ. Extracorporeal shockwave therapy in musculoskeletal disorders, j. J Orthop Surg Res .ther.7:11, 2012.

5. Ogden JA, Toth-Kischkat A, Schultheiss R, Principles of shock wave therapy.J. Clin Orthop Relat Res.there. 387:8-17,2001.

6. Ueberle F, Extracorporeal Shock Waves in Orthopaedics .J. ORS.there pp59-87, 1998

7. Van Tulder MW, Koes B, Seitsalo S, Malmivaara A, Outcome of invasive treatment modalities on back pain and sciatica: an evidence-based review. J. Spine, there. 15: 82-92, 2006.

8. Schlaudraff KU, Kiessling MC, Császár NBM, Schmitz C, Predictability of the individual clinical outcome of extractorporeal shock wave therapy for cellulite.J.PLOS One.t here. 7: 171-183, 2014. 
9. Sangyong Lee, $\mathrm{PhD}, \mathrm{PT}$, Daehee Lee, $\mathrm{PhD}$, PT, and Jungseo Park, PhD, PT, Effects of Extracorporeal Shockwave Therapy on Patients with Chronic Low Back Pain and Their Dynamic Balance Ability.J. PhysTher Sci. Jan; 26(1): 7-10, 2014.

10. Chan Park, MS, PT, Sangyong Lee, PhD, PT, Chae-Woo Yi, MSc, PT, and Kwansub Lee, $\mathrm{PhD}$, The effects of extracorporeal shock wave therapy on frozen shoulder patients' pain and functions.J. Phys Ther Sci ; 27(12): 3659-3661.2015.

11. Hammer DS, Rupp S, Ensslin S, Kohn D, Seil R, Extracorporal shock wave therapy in patients with tennis elbow and painful heel.J.Arch Orthop Trauma Surg.there. 120(5-6):304-7, 2000.

12. Speed CA, Nichols D, Richards C, Humphreys H, Wies JT, Burnet S, Hazleman BL, Extracorporeal shock wave therapy for lateral epicondylitis-a double blind randomised controlled trial. J Orthop Res.there. 22(5):895-898, 2002. 